\title{
Obesity and kidney stone disease: a systematic review
}

\author{
Antonio CARBONE 1,2, Yazan AL SALHI ${ }^{1}$, Andrea TASCA ${ }^{3}$, \\ Giovanni PALLESCHI 1, 2, Andrea FUSCHI ${ }^{1}$, Cosimo DE NUNZIO 4, Giorgio BOZZINI 5 , \\ Sandro MAZZAFERRO ${ }^{6}$, Antonio L. PASTORE 1,2 *
}

${ }^{1}$ Unit of Urology, Department of Medico-Surgical Sciences and Biotechnologies, Faculty of Pharmacy and Medicine, Sapienza University of Rome, Latina, Italy; ${ }^{2}$ Uroresearch, No Profit Research Association, Latina, Italy; ${ }^{3}$ Department of Medicine, International University for Peace, Rome, Italy; ${ }^{4}$ Department of Urology, Sant'Andrea Hospital, Rome, Italy; 5 Department of Urology, Mater Domini Humanitas, Castellanza, Varese, Italy; 6Unit of Nephrology and Hemodialysis, Department of Medico-Surgical Sciences and Biotechnologies, Faculty of Pharmacy and Medicine, Sapienza University of Rome, Latina, Italy

*Corresponding author: Antonio L. Pastore, Unit of Urology, Department of Medico-Surgical Sciences and Biotechnologies, Faculty of Pharmacy and Medicine, Sapienza University of Rome, Via F. Faggiana 1668, 04100 Latina, Italy.

E-mail: antonioluigi.pastore@uniroma1.it

\section{A B S T R A C T}

INTRODUCTION: Currently, abdominal obesity has reached an epidemic stage and obesity represents an important challenge for worldwide health authorities. Epidemiologic studies have demonstrated that the stone risk incidence increases with Body Mass Index, through multiple pathways. Metabolic syndrome and diabetes are associated with an increased renal stones disease incidence. The aim of this systematic review was to investigate the prevalence, morbidity, risk factors involved in the association between obesity and urolithiasis.

EVIDENCE ACQUISITION: The search involved finding relevant studies from MEDLINE, EMBASE, Ovid, the Cochrane Central Register of Controlled Trials, CINAHL, Google Scholar, and individual urological journals between January 2001 and May 2017. The inclusion criteria were for studies written in the English language, reporting on the association between obesity and urinary stones.

EVIDENCE SYNTHESIS: The underlying pathophysiology of stone formation in obese patients is thought to be related to insulin resistance, dietary factors, and a lithogenic urinary profile. Uric acid stones and calcium oxalate stones are observed frequently in these patients. Insulin resistance is thought to alter the renal acid-base metabolism, resulting in a lower urine $\mathrm{pH}$, and increasing the risk of uric acid stone disease. Obesity is also associated with excess nutritional intake of lithogenic substances and with an increase in urinary tract infection incidence. Recent studies highlighted that renal stone disease increases the risk of myocardial infarction, progression of chronic kidney disease, and diabetes. Contemporary, bariatric surgery has been shown to be associated with hyperoxaluria and oxalate nephropathy. Certainly, the many health risks of obesity, including nephrolithiasis, will add more burden on urologists and nephrologists.

CONCLUSIONS: Obesity related nephrolithiasis seems to necessitate weight loss as primary treatment, but the recognition of the associated complications is necessary to prevent induction of new and equally severe medical problems. The optimal approach to obesity control that minimizes stone risk needs to be determined in order to manage obesity-induced renal stones disease.

(Cite this article as: Carbone A, Al Salhi Y, Tasca A, Palleschi G, Fuschi A, De Nunzio C, et al. Obesity and kidney stone disease: a systematic review. Minerva Urol Nefrol 2018;70:393-400. DOI: 10.23736/S0393-2249.18.03113-2)

KEY WORDS: Obesity - Kidney calculi - Insulin resistance - Uric acid - Hypercalciuria - Metabolic syndrome.

\section{Introduction}

A ccording to WHO esteem, obesity is rapidly growing in the normal population and this seems to be dependent on diet and sedentary life style as a consequence of technological progress. The number of overweight people, that means people with a Body Mass Index (BMI) $>25 \mathrm{~kg} /$ $\mathrm{m}^{2}$, was expected to grow from 1.6 million in 2005 , to 3.3 million in 2015 . Furthermore, the 


\section{COPYRIGHT $^{\circledR} 2018$ EDIZIONI MINERVA MEDICA}

number of obese subjects, that means people with a BMI $>30$, will increase from 400 million to 700 million in the same time span. ${ }^{1}$

On the other hand, the association between BMI and urolithiasis has been frequently reported, with a prevalence of obesity in patients with kidney stone disease that varies, in the different studies, from $10 \%$ to $35 \% .^{2-5}$ Curhan et al. in a cross-sectional analysis of Nurses' Health Study (NHS; N. $=89,376$ women) and the Health Professionals Follow-up Study (HPFS), documented that the prevalence of stone disease was directly correlated to BMI for both women and men. ${ }^{6}$ These results were, subsequently, confirmed by Taylor et al. who further underlined the effect of an increasing magnitude of obesity on the risk of kidney stone formation. ${ }^{7}$

According to a recent report, regarding the history of stone formation in a population of more than 12.000 participants, included in the 2007-2010 National Health and Nutrition Examination Survey (NHANES), the prevalence of nephrolithiasis in the USA is $8.4 \% .{ }^{8}$ In men, the relative increase of stone formation, compared to 1988-1994 NHANES data, was 63\% (from 6.3\% to $10.3 \%){ }^{8}$ The prevalence of kidney stones appeared to be higher among obese individuals $(11.2 \%)$ and overweight individuals $(9.1 \%)$ when compared to individuals of normal weight (6.1\%). Moreover, a statistically significant correlation between kidney stone formation and obesity was observed at the multivariate analysis. Semings et al. investigated 95,598 subjects included in a national private insurance database, who were submitted to a median observation period of approximately 3 and half years. ${ }^{2}$ Overall the diagnosis of a kidney stone was done in $3.4 \%$ of the sample. During the evaluation period, $2.6 \%$ of subjects with a BMI less than $30 \mathrm{~kg} / \mathrm{m}^{2}$ and $4.9 \%$ of subjects with a BMI greater than $30 \mathrm{~kg} /$ $\mathrm{m}^{2}$ were diagnosed with a kidney stone. Except for men with a BMI greater than $50 \mathrm{~kg} / \mathrm{m}$, obese people were more frequently associated with a diagnosis of kidney stone compared to non-obese patients. $^{2}$ Notably, this year the world kidney day was dedicated to the hidden consequences of obesity on kidney diseases. ${ }^{9}$ Obesity causes both development of kidney disease and progression towards end stage renal failure. The mecha- nisms whereby obesity produce renal damage remain still unclear. Nephrolithiasis is considered, among authors, one of the possible factors that contribute to increase the burden of renal damage carried by obesity.

\section{Evidence acquisition}

The objective of this systematic review was to investigate the prevalence, morbidity, risk factors, and the association between obesity and urolithiasis.

\section{Search strategy}

The search involved finding relevant studies from MEDLINE, EMBASE, Ovid, the Cochrane Central Register of Controlled Trials, CINAHL, Google Scholar, and individual urological journals between January 2001 and May 2017. The review was conducted in accordance with the systematic review guidelines provided by the Cochrane Collaboration and the Preferred Reporting Items for Systematic Reviews and MetaAnalyses (PRISMA). Two reviewers (ALP and GP) independently identified all studies that fitted the inclusion criteria for this review, and any discrepancy was resolved after adjudication and consensus with the senior author (AT). The search terms included the following 'obesity,' 'insulin resistance,' 'uric acid, 'hypercalciuria,' 'metabolic syndrome,' 'bariatric surgery,' 'renal,' 'calculi,' 'stone(s),' 'urolithiasis'. These terms were combined using Boolean operators (AND, OR) to refine the search. The inclusion criteria focused on studies written in the English language, reporting on the association between obesity and urinary stones. Papers dealing with case reports and pediatric patients were not included. The studies fitting the inclusion criteria were analyzed for the following: journal of publication, period of review, type of study, country of origin, population demographics (age, sex, $\mathrm{BMI})$, stone composition.

\section{Evidence synthesis}

A total of 74 studies were identified from the literature search, 54 of which fitted completely the inclusion criteria (Figure 1). Among the ex- 


\section{COPYRIGHT $^{\odot} 2018$ EDIZIONI MINERVA MEDICA}

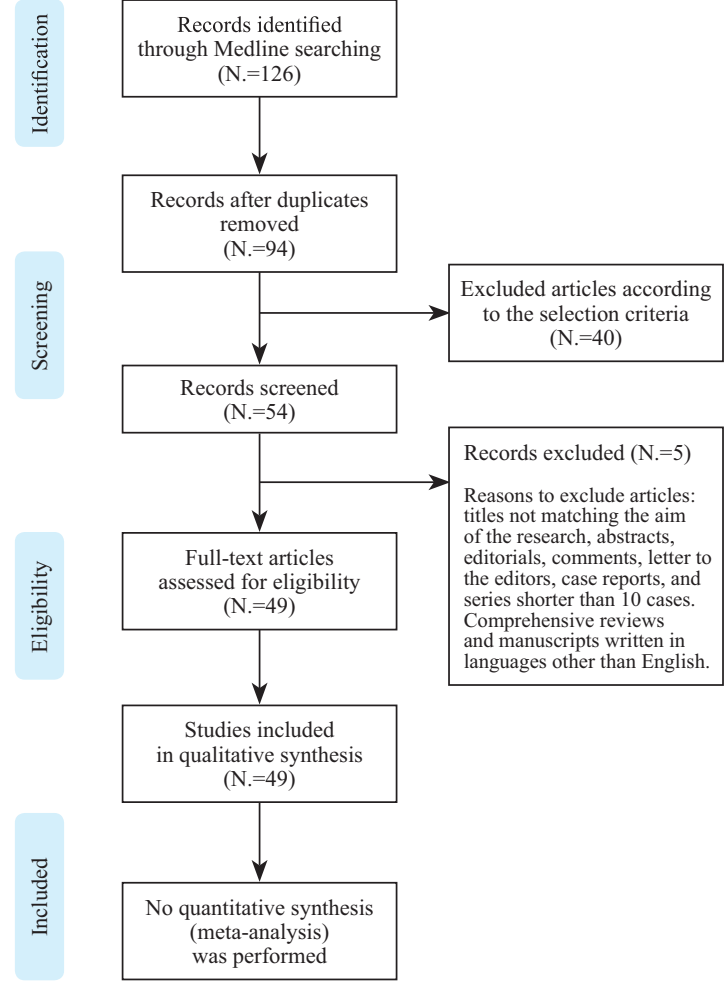

Figure 1.-PRISMA flow diagram summarizing literature review.

cluded articles, two papers were case reports, one comment, and two papers where an updated article was available from the same authors.

\section{BMI and urine composition}

The studies investigating the influence of obesity on 24-hour urine composition in stone patients failed to give homogeneous results. Urine $\mathrm{pH}$, an important factor for uric acid precipitation in urine, appeared to be inversely related to BMI in a study relative to a large number of patients with kidney stones. ${ }^{10}$ In another study of nearly 6000 stone formers, Powell documented an increased urinary excretion of oxalate, calcium and uric acid in subjects weighing more than $120 \mathrm{~kg}$ compared to subjects weighing less than $100 \mathrm{~kg}$. However urinary concentration of calcium and oxalate were similar in the 2 groups of patients due to differences in urine volume. ${ }^{11}$ Ekeruo reported a greater prevalence of hypercalciuria, hyperoxaluria and hyperuricosuria in an obese population of stone formers compared to a non-obese population. ${ }^{4}$
Taylor et al. found a difference in the urine composition of both stone-forming and nonstone-forming subjects included in the Health Professionals Follow up study and Nurses' health study I and II. ${ }^{12}$ Participants with greater BMI had lower urinary $\mathrm{pH}$ values and excreted more urinary oxalate, uric acid, sodium and phosphate compared to participants with lower BMI. A positive correlation between BMI and urinary calcium excretion was found only in men, independently on the presence of stones, and stoneforming younger women. This correlation however did not persist after adjustment for urinary phosphate and sodium excretion, suggesting that dietary proteins and sodium, rather than BMI determined the results. In this study a greater relative super-saturation of uric acid, but not of calcium oxalate, was found to be associated with the increasing BMI. ${ }^{12}$ Seiner examined a population of more than 500 calcium oxalate stone former and found a linear correlation between urinary calcium excretion and BMI only in male subjects. ${ }^{13} \mathrm{~A}$ linear correlation between urinary calcium and BMI was found by Nouvenne in the group of female patients with idiopathic calcium nephrolithiasis, but not in the group of female controls. ${ }^{14}$

Negri examined a population of over 700 stone formers, $61 \%$ of whom had a BMI $>25$, and found a significant increase of urinary oxalate, uric acid, phosphate and sodium with the increase of BMI, in both male and female patients. ${ }^{3}$ On the contrary no correlation was found, for both males and females, between urinary calcium and BMI. In this study citraturia was correlated with BMI only in the female population. ${ }^{3}$

The reviewed literature indicates that obesity is associated with an increased urinary excretion of solutes responsible for stone formation, including calcium, oxalate and sodium and with a low urine $\mathrm{pH}$. These abnormalities are partially counterbalanced by the increased urinary volume and citrate excretion.

\section{Physiopathology}

According to Leman, body size is the major determinant for urinary oxalate excretion among healthy adults, presumably reflecting variations 


\section{COPYRIGHT $^{\circledR} 2018$ EDIZIONI MINERVA MEDICA}

in endogenous oxalate synthesis with lean body mass. ${ }^{15}$ This finding, translated into the population of stone formers, could justify the positive correlation between urinary oxalate excretion and BMI, frequently found in patients with nephrolithiasis. $2,3,6,11$

In population studies, a positive correlation between urinary calcium excretion and body size was frequently reported.4,11,13 It is well known that one of the characteristics of obesity is insulin resistance. As insulin is supposed to increase renal fractional excretion of calcium, it would be reasonable to speculate that insulin resistance is one of the mechanisms responsible for the higher calcium excretion in the obese stone former. ${ }^{16,17}$ On the other hand, the influence of diet on calcium excretion in the obese stone former, must be taken in account.

In the study of Taylor et al., participants with higher BMI consumed more animal proteins and sodium (2 factors which increase urinary calcium excretion), than their lower BMI counterparts. ${ }^{12}$ In fact, the positive correlation between body size and calcium excretion, found in men and young stone forming women, did not persist after correction for phosphate and sodium. According to these results, the positive correlation between calcium excretion and BMI, frequently reported in previous studies, could be diet dependent rather than secondary to modifications of renal physiology. In Taylor's study, urinary saturation with respect to calcium oxalate and brushite appear to be normal in the obese population, as a possible consequence of an increase of urinary volume and citrate excretion. In fact, urinary citrate has previously been reported by some Authors to be increased in the obese population, as a consequence of excessive assumption of fattening food and drinks..$^{4,11}$

Increased uric acid excretion as well as a low urinary $\mathrm{pH}$, are both responsible of urinary supersaturation with respect to uric acid, found in patients with $\mathrm{BMI}>30 .{ }^{10,12}$ Urinary $\mathrm{pH}<5.5$ which corresponds to $\mathrm{pK}$ of uric acid, is supposed to be dependent on insulin resistance which, by the activation of the exchanger $\mathrm{NH} 3$ in the proximal renal tubule, reduces the synthesis and urinary excretion of ammonium. ${ }^{18-20}$ In acid urine, uric acid is present under undissociated, easily precipitable form so that uric acid stone formation can easily take place. ${ }^{21}$ An excess of uric acid in urine can, also, induce the precipitation of calcium oxalate dehydrate, by a process of heterogeneous nucleation. ${ }^{22}$

Since an inverse correlation between BMI and urinary $\mathrm{pH}$ persists even after correction for urinary sulfate, it is supposed that insulin resistance is independent on diet. ${ }^{9}$ This hypothesis is also supported by 2 observations: low glucose availability, caused by insulin resistance, is inversely correlated to urine $\mathrm{pH}$; uric acid urolithiasis is more frequent in stone patients with diabetes mellitus compared to non-diabetic patients. ${ }^{20,23}$ Metabolic abnormalities responsible for stone formation in obesity, such as hypercalciuria and low urine $\mathrm{pH}$, are mainly dependent on insulin resistance and partially on diet. Oxalate excretion is potentially related to body habitus and citrate excretion is diet dependent.

Prevalence of metabolic risk factors and clinical evolution of nephrolithiasis

Hypercalciuria, gouty diathesis, hypocitraturia and a low urinary volume were found in more than $50 \%$ of obese patients included in a nephrolithiasis database. ., 24 Other reported metabolic defects included hyperoxaluria and high urinary excretion of sulfate. All these metabolic abnormalities were statistically more represented in the obese compared to non-obese stone formers ${ }^{4}$ (Table I). Furthermore, urinary $\mathrm{pH}$ decreased, whereas the severity of hypercalciuria and hyperuricosuria increased with the severity of obesity as determined by BMI.

Lee et al. conducted a study on more than 700 stone formers (SF) and found that hypercalciuria, hyperuricosuria and low urinary volume were highly represented among obese patients as compared to non-obese patients. ${ }^{24}$ On the

TABLE I.-Prevalence of patients presenting metabolic risk factors. ${ }^{4}$

\begin{tabular}{lcc}
\hline & \% Obese group & \% Non-obese group \\
\hline Gouty diathesis & 54 & 18 \\
Hyperuricosuria & 43 & 20 \\
Hypercalciuria & 59 & 48 \\
Hypocitraturia & 54 & 63 \\
Hyperoxaluria & 31 & 10 \\
High urine sulfate & 70 & 24 \\
Low urine volume & 58 & 70 \\
\hline
\end{tabular}




\section{COPYRIGHT $^{\circledR} 2018$ EDIZIONI MINERVA MEDICA}

contrary, the percentage of hypocitraturia was significantly lower among obese SF compared with non-obese SF. Clinical evolution of nephrolithiasis, including time to stone recurrence, was correlated to obesity only in patients at the first stone episode. These patients had a percentage of stone relapse at 5 years significantly higher in comparison to patients with normal weight $(42 \%$ vs. $14.9 \% ; \mathrm{P}<0.012$ ) and obesity was the only predictor of stone recurrence at the multivariate analysis. On the other hand, in patients with recurrent nephrolithiasis, the percentage of stone relapse was not statistically different in obese and non-obese stone formers $(44.7 \% v s .53 .3 \%)$ and hypercalciuria was the only predicting factor at the multivariate analysis. ${ }^{24}$

In the study conducted by Ekeruo et al. selective medical therapy proved to be useful in correcting metabolic abnormalities and preventing stone recurrence in both normal weight and obese stone formers. ${ }^{4}$ Potassium citrate and allopurinol were the most frequently administered drug for the correction of gouty diathesis, hypocitraturia and unusually acidic urine. Moreover, all obese patients received dietary recommendations, aiming specifically at the decreasing animal protein intake. Normalization of urinary calcium, citrate, sulfate and uric acid was obtained in the majority of patients and these results translated into a decrease in the number of new stones formed yearly per patient (from 1.8 to 0.1 ). ${ }^{4}$

According to current evidence, metabolic defects favoring stone formation are more represented in the obese patients than in the normal weight counterparts. However, selective medical therapy seems to be effective in preventing stone relapses independently on BMI.

\section{BMI and stone composition}

Daudon compared stone composition and anthropometric data relative to more than 2000 stone patients and documented the major influence of an increasing BMI on the risk of forming uric acid (UA) stones. ${ }^{5}$ In this paper $92.9 \%$ normal weight males produced calcium containing stones. This percentage was significantly higher compared to that found in the overweight group (88.7 vs. 92.9\%, $\mathrm{P}=0.011$ ) and, even more, in the obese group (71.3 vs. 92.9\%, $\mathrm{P}<0.0001)$. Con- versely, the percentage of UA stones raised with BMI in the male population, from $7.1 \%$ in normal BMI to $11.3 \%$ in overweight and $28.7 \%$ in obese patients $(\mathrm{P}<0.0001)$. The same trend was observed in the female patients. The percentage of UA stones raised from $6.1 \%$ in the normal BMI group to $12.7 \%$ in overweight and up to $17.1 \%$ in obese groups $(\mathrm{P}=0.003)$. Moreover, the influence of overweight was mainly apparent in patients under 60-65 years of age, whereas an increasing age was the major factor in older subjects. Because a decreased ammonium excretion resulting in a lower urinary $\mathrm{pH}$ is frequent in the elderly, age-associated defective urinary acidification may be the major contributing factor to uric acid stone formation in older subjects. ${ }^{25-27}$ The analysis of more than 400 stones among obese patients, revealed that calcium oxalate monohydrated (66\%) and uric acid (63\%) were the prevalent components, followed by calcium oxalate dehydrated (31\%). ${ }^{4}$ On the other hand, calcium oxalate monohydrated (88\%) and dehydrated $(68 \%)$ and apatite $(68 \%)$ were the most common compositions in the non-obese group, in which uric acid stones were detected in $11 \%$ of patients.

On the base of current literature there are convincing arguments that lead to suggest a role of obesity in favoring the formation of uric acid stones, where the major risk factors is represented by low urine $\mathrm{pH}$ and hyperuricosuria. ${ }^{27}$

\section{Metabolic syndrome and kidney stone disease}

The metabolic syndrome (MetS) is a clinical entity characterized by the presence of the following traits: obesity, dyslipidemia, hypertension and impaired glucose tolerance or diabetes mellitus. ${ }^{28}$ This syndrome of which obesity is supposed to be the driving component, is associated with an increased risk of cardiovascular disease, hyperuricemia and chronic kidney disease. According to community-based and a hospital-based studies, the prevalence of MetS is increased over the last decade to $30 \% .^{29,30} \mathrm{In}$ the Third National Health and Nutrition Examination Survey, the prevalence of nephrolithiasis in individuals with MetS appeared to be $8.8 \%$ and it was shown to rise progressively with the number of MetS traits: 3\% with zero traits, 7.5\% with three traits and $9.8 \%$ with five traits. ${ }^{31}$ In 


\section{COPYRIGHT $^{\circledR} 2018$ EDIZIONI MINERVA MEDICA}

CARBONE

OBESITY AND KIDNEY STONE DISEASE

the study of Rendina et al., 34\% of an inpatient population of more than 2 thousand subjects had a positive diagnosis of MetS and $10.3 \%$ of them had an evidence of nephrolithiasis at ultrasound. The sonographic study documented a two-fold greater occurrence of nephrolithiasis in MetS patients compared with the remaining inpatient population. Cox analysis revealed that there was an independent significant correlation among the evidence of renal stones, on one side and the diagnosis of MetS and the past history of KSD, on the other. ${ }^{32}$ These data appear to be confirmed in the study of Jeong et al. relative to a screened population of approximately 35 thousand Korean subjects. The presence of MetS had an OR of 1.25 for kidney stone prevalence detected on the base of CT scan or sonography. ${ }^{33}$ Kohjimoto et al. in the retrospective analysis of 30,448 patients with urolithiasis, found a stepwise correlation between the presence of one or more traits of MetS and the severity of kidney stone disease. ${ }^{34}$ In this study, multivariate analysis revealed that the presence of MetS traits was associated not only with recurrent or multiple kidney stones, but also with the presence of abnormalities in urine constituents such as hypercalciuria, hyperuricosuria and hypocitraturia. Besides insulin resistance that is strictly associated with obesity, the higher incidence of KSD could be induced by chronic inflammation, which is responsible of the complex metabolic derangements of MetS. 35 , 36 Recent studies suggest that the expression of inflammatory molecules, such as monocyte chemo attractant protein 1 and osteopontin, and macrophage infiltration, activate the early phases of kidney stone formation. ${ }^{36,37}$

In conclusion, the available data suggest that there is a link between MetS and nephrolithiasis and that the clinical activity of stone disease is directly correlated with the severity of MetS $^{35-38}$ (Table II). 29, 32-34, 38

\section{Bariatric surgery and new stone formation}

According to large, randomized trials, patients who undergo bariatric surgery have sustained weight loss, decreased mortality and a lower incidence of obesity-related complications, such as diabetes, hypertension, cardiovascular disease and obstructive sleep apnea. ${ }^{39,} 40$ Among the different surgical techniques, Roux-en-Y gastric bypass (RYGB), a mixed malabsorptive/restrictive operation, has represented, in recent years, the most popular bariatric procedure. ${ }^{41}$ However, both laboratory and clinical studies, have found that RYGB may be associated with enteric hyperoxaluria and an increased risk of nephropathy and kidney stone disease. ${ }^{42-44}$ On the contrary, hyperoxaluria does not seem to arise after restrictive techniques, such as sleeve gastrectomy and adjustable lap banding, which are not reported to be associated with a consistent risk of kidney stone formation. ${ }^{45-47}$ This observation was confirmed by Lieske who compared 759 patients who underwent bariatric surgery to a matched group of obese patients belonging to the Olmsted County. BMI was 46 for both groups and neph-

TABLE II.-Major studies reporting association of MetS and kidney stones.

\begin{tabular}{|c|c|c|c|c|}
\hline Authors & $\begin{array}{l}\text { Risk factors } \\
\text { studied }\end{array}$ & Patients & Follow-up & Results \\
\hline Kohjimoto $^{34}$ & MetS & 30,448 & N/A & $\begin{array}{l}\text { Recurrence of multiple stones related with traits of MetS: } \\
\text { zero } 57.7 \% \\
\text { one } 61.7 \% \\
\text { two } 65.2 \% \\
\text { three } 69.3 \% \\
\text { four } 73.3 \%\end{array}$ \\
\hline Rule $^{38}$ & $\begin{array}{l}\text { Myocardial } \\
\text { infarction }\end{array}$ & $\begin{array}{l}4564 \text { SF vs. } \\
10,845 \text { NSF }\end{array}$ & 9 years & OR for $\mathrm{MI}-1.35$ (stone formers had a $38 \%$ increased risk for MI) \\
\hline West 29 & MetS & 33,994 & $\mathrm{~N} / \mathrm{A}$ & $\begin{array}{l}\text { Prevalence of nephrolithiasis related with MetS traits: } \\
\text { 3\% with zero traits; } \\
7.5 \% \text { with three traits; } \\
9.8 \% \text { with five traits }\end{array}$ \\
\hline Rendina ${ }^{32}$ & MetS & 2132 & N/A & $10.3 \%$ echographic evidence of NL, while $9.3 \%$ past history of NL \\
\hline Jeong $^{33}$ & MetS & 34,895 & N/A & MetS OR 1.25 (95\% CI: 1.03-1.50) for kidney stone prevalence \\
\hline
\end{tabular}

MetS: Metabolic Syndrome; MI: myocardial infarction; NL: nephrolithiasis; OR: Odds Ratio. 


\section{COPYRIGHT $^{\circledR} 2018$ EDIZIONI MINERVA MEDICA}

rolithiasis at baseline had similar frequency in bariatric surgery patients and controls $(4.0 \% \mathrm{vs}$. $4.2 \%)$. Over a mean follow-up period of 6.0 (3.2) years, new stone events were found to be more common in bariatric surgery patients than in obese controls $(11.1 \%$ vs. $4.3 \%$; $\mathrm{P}<0.01)$. Stone risk was dependent on the choice of specific type of bariatric surgery, being greatest in malabsorptive procedures, intermediate in standard RYGB, and least in restrictive procedures. 48

Previously Matlaga identified 4639 patients who had undergone RYGB and 4639 obese controls, in a private insurance claims database. ${ }^{44}$ Over a median follow-up of 4 years, $7.65 \%$ of bariatric patients were shown to have developed a stone, compared with $4.63 \%$ of obese controls (odds ratio 1.71). The mean time from bariatric surgery to the stone event was 1.5 years, and RYGB patients were also more likely to undergo surgical stone removal (odds ratio 3.65). ${ }^{44}$

In conclusion bariatric surgery guarantees a longer survival and less comorbidities for the obese patient. These results, however, must be balanced against the fact that some bariatric procedures are associated with a consistent risk of kidney stone formation and nephropathy. 49

\section{Conclusions}

The correlation between obesity and urinary stone is proved by numerous epidemiological studies. The process of lithogenesis is activated by some urine abnormalities, which appear to be more represented in the obese compared to the normal weight patient. Uric acid is the main stone composition and insulin resistance and diet are the mechanisms responsible of stone formation. Patients with metabolic syndrome seem to be as well affected by nephrolithiasis and there is a correlation between the presence of one or more traits of MetS and the severity of kidney stone disease. The benefits of bariatric surgery must be weighed in light of the possible subsequent onset of fat malabsorption and hyperoxaluria which can lead to kidney stone formation and renal insufficiency. Hopefully in the next future, the discovery of the metabolic pathways leading lithiasis in obese patients will help to find more specific preventive therapies.

\section{References}

1. Levy DT, Mabry PL, Wang YC, Gortmaker S, Huang TT, Marsh T, et al. Simulation models of obesity: a review of the literature and implications for research and policy. Obes Rev 2011;12:378-94.

2. Semins MJ, Shore AD, Makary MA, Magnuson T, Johns $\mathrm{R}$, Matlaga BR. The association of increasing body mass index and kidney stone disease. J Urol 2010;183:571-5.

3. Negri AL, Spivacow FR, Del Valle EE, Forrester M, Rosende G, Pinduli I. Role of overweight and obesity on the urinary excretion of promoters and inhibitors of stone formation in stone formers. Urol Res 2008;36:303-7.

4. Ekeruo WO, Tan YH, Young MD, Dahm P, Maloney ME, Mathias BJ, et al. Metabolic risk factors and the impact of medical therapy on the management of nephrolithiasis in obese patients. J Urol 2004;172:159-63.

5. Daudon M, Lacour B, Jungers P. Influence of body size on urinary stone composition in men and women. Urol Res 2006;34:193-9.

6. Curhan GC, Willett WC, Rimm EB, Speizer FE, Stampfer MJ. Body size and risk of kidney stones. J Am Soc Nephrol 1998;9:1645-52.

7. Taylor EN, Stampfer MJ, Curhan GC. Obesity, weight gain, and the risk of kidney stones. JAMA 2005;293:455-62.

8. Scales CD Jr, Smith AC, Hanley JM, Saigal CS; Urologic Diseases in America Project. Prevalence of kidney stones in the United States. Eur Urol 2012;62:160-5.

9. Kovesdy CP, Furth SL, Zoccali C; World Kidney Day Steering Committee. Electronic address: myriam@worldkidneyday.org; World Kidney Day Steering Committee. Obesity and kidney disease: hidden consequences of the epidemic. Kidney Int 2017;91:260-2.

10. Maalouf NM, Sakhaee K, Parks JH, Coe FL, Adams-Huet $\mathrm{B}$, Pak CY. Association of urinary $\mathrm{pH}$ with body weight in nephrolithiasis. Kidney Int 2004;65:1422-5.

11. Powell CR, Stoller ML, Schwartz BF, Kane C, Gentle $\mathrm{DL}$, Bruce JE, et al. Impact of body weight on urinary electrolytes in urinary stone formers. Urology 2000;55:825-30.

12. Taylor EN, Curhan GC. Body size and 24-hour urine composition. Am J Kidney Dis 2006;48:905-15.

13. Siener R, Glatz S, Nicolay C, Hesse A. The role of overweight and obesity in calcium oxalate stone formation. Obes Res 2004;12:106-13.

14. Nouvenne A, Ticinesi A, Allegri F, Guerra A, Guida L, Morelli I, et al. Twenty-five years of idiopathic calcium nephrolithiasis: has anything changed? Clin Chem Lab Med 2014;52:337-44.

15. Lemann J Jr, Pleuss JA, Worcester EM, Hornick L, Schrab D, Hoffmann RG. Urinary oxalate excretion increases with body size and decreases with increasing dietary calcium intake among healthy adults. Kidney Int 1996;49:200-8.

16. Kerstetter J, Caballero B, O'Brien K, Wurtman R, Allen L. Mineral homeostasis in obesity: effects of euglycemic hyperinsulinemia. Metabolism 1991;40:707-13.

17. Nowicki M, Kokot F, Surdacki A. The influence of hyperinsulinaemia on calcium-phosphate metabolism in renal failure. Nephrol Dial Transplant 1998;13:2566-71.

18. Chobanian MC, Hammerman MR. Insulin stimulates ammoniagenesis in canine renal proximal tubular segments. Am J Physiol 1987;253:F1171-7.

19. Klisic J, Hu MC, Nief V, Reyes L, Fuster D, Moe OW, et al. Insulin activates $\mathrm{Na}(+) / \mathrm{H}(+)$ exchanger 3: biphasic response and glucocorticoid dependence. Am J Physiol Renal Physiol 2002;283:F532-9. 


\section{COPYRIGHT $^{\odot} 2018$ EDIZIONI MINERVA MEDICA}

20. Abate N, Chandalia M, Cabo-Chan AV Jr, Moe OW, Sakhaee K. The metabolic syndrome and uric acid nephrolithiasis: novel features of renal manifestation of insulin resistance. Kidney Int 2004;65:386-92.

21. Pak CY, Sakhaee K, Peterson RD, Poindexter JR, Frawley WH. Biochemical profile of idiopathic uric acid nephrolithiasis. Kidney Int 2001;60:757-61.

22. Coe FL, Strauss AL, Tembe V, Le Dun S. Uric acid saturation in calcium nephrolithiasis. Kidney Int 1980;17:662-8.

23. Pak CY, Sakhaee K, Moe O, Preminger GM, Poindexter $\mathrm{JR}$, Peterson RD, et al. Biochemical profile of stone-forming patients with diabetes mellitus. Urology 2003;61:523-7.

24. Lee SC, Kim YJ, Kim TH, Yun SJ, Lee NK, Kim WJ. Impact of obesity in patients with urolithiasis and its prognostic usefulness in stone recurrence. J Urol 2008;179:570-4.

25. Agarwal BN, Cabebe FG. Renal acidification in elderly subjects. Nephron 1980;26:291-5.

26. Hesse A, Classen A, Knoll M, Timmermann F, Vahlensieck W. Dependence of urine composition on the age and sex of healthy subjects. Clin Chim Acta 1986;160:79-86.

27. Kim JH, Doo SW, Cho KS, Yang WJ, Song YS, Hwang J, et al. Which anthropometric measurements including visceral fat, subcutaneous fat, body mass index, and waist circumference could predict the urinary stone composition most? BMC Urol 2015;15:17.

28. Grundy SM, Cleeman JI, Daniels SR, Donato KA, Eckel RH, Franklin BA, et al.; American Heart Association; National Heart, Lung, and Blood Institute. Diagnosis and management of the metabolic syndrome: an American Heart Association/National Heart, Lung, and Blood Institute Scientific Statement. Circulation 2005;112:2735-52.

29. West B, Luke A, Durazo-Arvizu RA, Cao G, Shoham D, Kramer H. Metabolic syndrome and self-reported history of kidney stones: the National Health and Nutrition Examination Survey (NHANES III) 1988-1994. Am J Kidney Dis 2008;51:741-7.

30. Rendina D, Mossetti G, De Filippo G, Benvenuto D, Vivona CL, Imbroinise A, et al. Association between metabolic syndrome and nephrolithiasis in an inpatient population in southern Italy: role of gender, hypertension and abdominal obesity. Nephrol Dial Transplant 2009;24:900-6.

31. Wong Y, Cook P, Roderick P, Somani BK. Metabolic Syndrome and Kidney Stone Disease: A Systematic Review of Literature. J Endourol 2016;30:246-53.

32. Rendina D, De Filippo G, D’Elia L, Strazzullo P. Metabolic syndrome and nephrolithiasis: a systematic review and meta-analysis of the scientific evidence. J Nephrol 2014;27:371-6.

33. Jeong IG, Kang T, Bang JK, Park J, Kim W, Hwang SS, et al. Association between metabolic syndrome and the presence of kidney stones in a screened population. Am J Kidney Dis 2011;58:383-8.

34. Kohjimoto Y, Sasaki Y, Iguchi M, Matsumura N, Inagaki T, Hara I. Association of metabolic syndrome traits and se- verity of kidney stones: results from a nationwide survey on urolithiasis in Japan. Am J Kidney Dis 2013;61:923-9.

35. Eckel RH, Grundy SM, Zimmet PZ. The metabolic syndrome. Lancet 2005;365:1415-28.

36. Tran TY, Flynn M, O'Bell J, Pareek G. Calculated insulin resistance correlates with stone-forming urinary metabolic changes and greater stone burden in high-risk stone patients. Clin Nephrol 2016;85:316-20.

37. Jung $\mathrm{H}$, Andonian S, Assimos D, Averch T, Geavlete $\mathrm{P}$, Kohjimoto Y, et al. Urolithiasis: evaluation, dietary factors, and medical management: an update of the 2014 SIU-ICUD international consultation on stone disease. World J Urol 2017;35:1331-40.

38. Rule AD, Roger VL, Melton LJ 3rd, Bergstralh EJ, Li X, Peyser PA, et al. Kidney stones associate with increased risk for myocardial infarction. J Am Soc Nephrol 2010;21:1641-4. 39. Carlsson LM, Peltonen M, Ahlin S, Anveden Å, Bouchard C, Carlsson B, et al. Bariatric surgery and prevention of type 2 diabetes in Swedish obese subjects. N Engl J Med 2012;367:695-704.

40. Sjöström L, Peltonen M, Jacobson P, Sjöström CD, Karason $\mathrm{K}$, Wedel $\mathrm{H}$, et al. Bariatric surgery and long-term cardiovascular events. JAMA 2012;307:56-65.

41. Smith BR, Schauer P, Nguyen NT. Surgical approaches to the treatment of obesity: bariatric surgery. Med Clin North Am 2011;95:1009-30.

42. Nelson WK, Houghton SG, Milliner DS, Lieske JC, Sarr MG. Enteric hyperoxaluria, nephrolithiasis, and oxalate nephropathy: potentially serious and unappreciated complications of Roux-en-Y gastric bypass. Surg Obes Relat Dis 2005;1:481-5.

43. Kumar R, Lieske JC, Collazo-Clavell ML, Sarr MG, Olson ER, Vrtiska TJ, et al. Fat malabsorption and increased intestinal oxalate absorption are common after Roux-en-Y gastric bypass surgery. Surgery 2011;149:654-61.

44. Matlaga BR, Shore AD, Magnuson T, Clark JM, Johns R, Makary MA. Effect of gastric bypass surgery on kidney stone disease. J Urol 2009;181:2573-7.

45. Tarplin S, Ganesan V, Monga M. Stone formation and management after bariatric surgery. Nat Rev Urol 2015;12:263-70.

46. Semins MJ, Asplin JR, Steele K, Assimos DG, Lingeman $\mathrm{JE}$, Donahue $\mathrm{S}$, et al. The effect of restrictive bariatric surgery on urinary stone risk factors. Urology 2010;76:826-9.

47. Chen T, Godebu E, Horgan S, Mirheydar HS, Sur RL. The effect of restrictive bariatric surgery on urolithiasis. J Endourol 2013;27:242-4.

48. Lieske JC, Mehta RA, Milliner DS, Rule AD, Bergstralh EJ, Sarr MG. Kidney stones are common after bariatric surgery. Kidney Int 2015;87:839-45.

49. Thongprayoon C, Cheungpasitporn W, Vijayvargiya P, Anthanont P, Erickson SB. The risk of kidney stones following bariatric surgery: a systematic review and meta-analysis. Ren Fail 2016;38:424-30.

Conflicts of interest.-The authors certify that there is no conflict of interest with any financial organization regarding the material discussed in the manuscript.

Authors' contributions.-Antonio Carbone and Yazan Al Salhi equally contributed to the drafting and the final revision of the manuscript, so they both have to be considered as first author. Antonio L. Pastore, Giovanni Palleschi, Andrea Fuschi, Yazan Al Salhi and Andrea Tasca carried out the data collection, and drafted the manuscript; Andrea Tasca, Antonio L. Pastore, Giovanni Palleschi, Sandro Mazzaferro and Antonio Carbone conceived of the study, and participated in its design and coordination and helped to draft the manuscript. All authors read and approved the final version of the manuscript.

Article first published online: May 31, 2018. - Manuscript accepted: May 23, 2018. - Manuscript revised: May 11, 2018. - Manuscript received: December 19, 2017. 